This is an electronic reprint of the original article. This reprint may differ from the original in pagination and typographic detail.

Author(s): Troyer, Robert A.; Szabó, Tamás Péter

Title: Representation and videography in linguistic landscape studies

Year: $\quad 2017$

Version:

Please cite the original version:

Troyer, R. A., \& Szabó, T. P. (2017). Representation and videography in linguistic landscape studies. Linguistic Landscape, 3(1), 56-77.

https://doi.org/10.1075/II.3.1.03tro

All material supplied via JYX is protected by copyright and other intellectual property rights, and duplication or sale of all or part of any of the repository collections is not permitted, except that material may be duplicated by you for your research use or educational purposes in electronic or print form. You must obtain permission for any other use. Electronic or print copies may not be offered, whether for sale or otherwise to anyone who is not an authorised user. 


\title{
Representation and Videography in Linguistic Landscape Studies
}

\author{
Robert A. Troyer \\ Western Oregon University \\ Tamás Péter Szabó \\ University of Jyväskylä
}

Much Linguistic Landscape scholarship relies on visual data collection, primarily the use of still photography; however, the field has yet to address the theoretical underpinning of such visual and spatial representation. Furthermore, digital video is currently as easy to capture and share as digital photographs were when Linguistic Landscape studies first became prominent in the early 2000s. With these two points in mind, this article first grounds the documentation and analysis of the Linguistic Landscape in a theory of visual representation; it then provides a framework for videographic methodologies drawing on recent work in the related fields of anthropology and cultural geography. An example study utilizing non-participatory videography is summarized in which digital video recordings were used to capture and convey the Linguistic Landscape.

Key words: Visual Representation; Technical Images; Videography; Methodology

\section{Introduction}

For those of us who are old enough to have been accustomed to traditional film-based photography, the memories, probably at least a decade old, of those first experiments with a digital camera remain vivid. A combination of electronic instant gratification, a passion to document the surrounding world, and freedom from the constraints of celluloid and chemistry enhanced by the fascination of a new toy. We captured hundreds of images in a single day, downloaded them to our PCs and Macs in minutes and browsed in awe of the potential.

It should come as no surprise that the exponential growth of Linguistic Landscape (LL) studies began after the widespread availability of relatively inexpensive hand-held digital cameras (see Gorter, 2006:2). The ability to quickly, easily, and affordably capture the visible displays of language in specific locations and reproduce them on the monitors in our offices and homes for detailed analysis was and is indispensable to the field of LL studies. Today, however, with cameras embedded in our mobile phones and digital video as easy to record, edit, and distribute as digital photos were ten years ago, we should acknowledge what scholars in anthropology and cultural geography have recognized, that video can capture, "the multisensory fluidity and rhythms of everyday life" conveying "an experiential stream of time in the field as a researcher, in the world as a participant, in the flux and flow of passage and encounter" (Garrett, 2010: 522). In this article we will begin with a discussion of photographic representation in LL studies-a topic that we feel has not been adequately addressed in LL publications. These concerns carry over to the uses of digital video to which we add a suggested framework for videographic methodologies in LL studies. This is followed by an example of how utilizing digital video to document the LL can offer a new way of seeing a landscape. 


\section{The allure of representation}

Unlike some areas of academic inquiry, the field of LL studies has immediate popular appeal especially to people who are interested in travel, language, and culture. At present there are several blogs devoted to linguistic landscapes as well as websites dedicated to displays of public signage and numerous individual blog entries about LL or signage on language or linguisticsthemed sites. Though these popularizations vary greatly in depth and quality, and we are encouraged by any public interest and awareness raising of language in the public sphere, these general-audience writings are typically not focused on the semiotics, sociocultural, or sociolinguistic aspects of the LL, but on displaying decontextualized images of LLs-see for example, <flickr.com/photos/mapurbanlinguisticlandscape/> which is connected to a WordPress blog and an active Facebook page with over 5000 members, created by Damien Williams and Stephen Greene. Furthermore, as LL studies and methods have reached a wider audience, and increasing numbers of university instructors assign LL projects conducted by students in foreign language, linguistics, and other courses, some theoretical background regarding visual images should be available in the LL literature. The appeal of photographs from places that are beyond our daily paths of travel is so strong that we feel even LL scholars need to be reminded of the distinction between the complexity of a landscape (Blommaert, 2013) and visual data collected from a landscape - a topic that to our knowledge has not been explicitly addressed in LL studies through a discussion of representational images in research.

From the late 1990s to the end of the first decade of the $21^{\text {st }}$ Century, the field of LL studies quickly expanded from defining the LL as language choice on "public road signs, advertising billboards, street names, place names, commercial shop signs, public signs on governmental buildings" (Landry \& Bourhis, 1997:25) to a broad semiotic construct that includes "all possible discourses that emerge in changing public spaces" (Shohamy \& Waksman, 2009:328). The inclusion in LL studies of skinscapes (Peck \& Stroud, 2015), smellscapes (Pennycook \& Otsuji, 2015), various internetscapes (Ivkovic \& Lotherington, 2009; Malinowski, 2010; Troyer, 2012), graffiti (Pennycook, 2009, 2010), the temporary landscapes of demonstrations and art installations (Blackwood, Lanza, \& Woldemariam, 2016; Kitis \& Milani, 2015; and chapters in Rubdi \& Ben Said, 2015), and the less public domain of schoolscapes (Brown, 2012; Gorter \& Cenoz, 2015; Szabó, 2015) is indicative of innovation and interdisciplinarity.

All of these -scapes are phenomenological embodiments of a living LL for which scholars using various theoretical lenses determine the abstract processes of complex social dynamics, structuration principles, semiotic systems, and discourses that directly affect identity, agency, indexicality, ideologies, commodification, and status all of which are relevant to multilingualism, language policies, globalization, and urbanization. Despite the depth of thought and interpretation that even the most quantitative of LL studies can inspire, despite the increase in qualitative data collection that produces insight on an LL from its agents, despite the detailed historical contexts that many LL studies provide, and despite the ethnographies that have enriched the field... the materiality of the LL is inescapable, compelling, and nearly always visible. Thus, it is imperative that we confront how we represent the visual in our work, lest we allow technology-dependence to influence how we conceptualize what we study and our role as researchers. 
A parallel example can be drawn from twentieth century variationist sociolinguistics, which was heavily influenced by increasingly portable technology for audio recording beginning in the 1960s, progressing from reel-to-reel to cassette to digital audio recorders. As Bucholtz \& Hall (2016) explain, for many years the field became "for the most part a disembodied undertaking" (177) from which most elements of visual communication and multimodality were ignored as scholars studied transcripts of vernacular language. With film recording and even analog video recording of the 1990s remaining prohibitively obtrusive for fieldwork, technology for data collection that was limited to audio recording became intertwined with theoretical orientations that favored "language as traditionally conceived" and "linguistic patterning rather than with the place of language in a broad communicative field encompassing the full range of embodied practices" (Bucholtz \& Hall, 2016: 177).

Just as the example from variationist sociolinguistics is not intended as a critique of that field's development, neither should pointing out the influence of photography in LL studies detract from work in this field which, beyond simply cataloguing languages in a setting, has always been concerned with underlying principles that shape the LL. Shohamy \& Gorter's (2009) introduction to Linguistic Landscape: Expanding the Scenery, begins, in part: "Language in spaces and places is calling for the attention of researchers and scholars who attempt to study and interpret its meaning, messages, purposes and contexts" (1).

Yet it seems odd to assert that a successful study of the LL of a specific location could be performed and published without the use of a camera, for while this is certainly true, it is rare (for example, Kallen's (2016) presentation titled, "Semiotic Landscapes and Literary Imagination in James Joyce's Ulysses"). Our experience of a place in time, our knowledge of its past and present including what we learn from local informants, and our ability to analyze data are enhanced by both the act and product of documenting the LL, most often using photographic images. In an age in which the creation and sharing of images has become ubiquitous via social media and mobile electronic devices, ${ }^{1}$ John Berger's (1973) definition of 'image'in Ways of Seeing bears reminding: "an image is a sight which has been recreated or reproduced. It is an appearance, or a set of appearances, which has been detached from the place and time in which it first made its appearance and preserved - for a few moments or a few centuries. Every image embodies a way of seeing. Even a photograph" (9-10). The process of stopping, pointing, and clicking, forces a simultaneous selectivity of focus and a distancing from lived experience, and the images we store for later perusal add color and shape to our notes, audio recordings, and memories. But LL studies have not addressed a fundamental element of representation: the camera is a tool. In Flusser's (1983) Towards a Philosophy of Photography, ${ }^{2}$ he explains,

Tools in the usual sense tear objects from the natural world in order to bring them to the place (produce them) where the human being is. In this process they change the form of these objects: They imprint a new, intentional form onto them. They 'inform' them: The object acquires an unnatural, improbable form; it becomes cultural (23).

Flusser contrasts two types of images, first addressing 'traditional' images such as drawings and paintings, which are the product of human interpretation of a three dimensional place or thing channeled through the body and onto a two dimensional medium of representation. On the other hand 'technical' images are produced from an apparatus, such as a camera, which transfers data from a sensor to a flat medium carrying the image; Flusser argues that these latter 
images with their 'accurate' representations of shape, perspective, and color, obscure the symbolic nature of the image. Observers easily recognize that a drawing is a 'theoretical' image, but the "apparently non-symbolic, objective character of technical images leads whoever looks at them to see them not as images but as windows" (15). The LL researcher scrolling through photos must be ever cognizant that the image is neither the LL nor a window onto the LL, that "what appears in the photograph are the categories of the camera which ensnare the cultural conditions like a net with a limited view through its mesh" (34).

Representations of the LL have enabled advances in the field, but the allure of images and the visual frames that they impose have shaped conceptualizations of the LL. Thus, Stroud \& Mbpendukana (2009), in their often cited article, suggest that "studies of linguistic landscape could move away from studying texts in spatially definable frames, to the study of the dialogicality of discourses across spaces and artifacts" (372; our emphasis). Discourse and emplacement of signs in the LL entail human agency and motivation, but LL studies primarily feature cropped photographs of tokens suggesting the perspective of a hypothetical inhabitant, rather like the Chomskyan conception of an idealized native speaker's competence.

A theoretical underpinning of representation is not only essential to understand the role of photography in LL studies, but even more pertinent if researchers begin to adopt videographic methodologies. Flusser additionally explains that the different media used to create technical images convey varying degrees of symbolism; for example, black and white photographs "reveal their theoretical origin more clearly, and vice versa: The 'more genuine' the colours of the photograph become, the more untruthful they are, more they conceal their theoretical origins" (44). By extension, video recordings are powerful because they provide "a sense of visiting places and witnessing events... few other media impart a more direct sense of being "there"" (Gold 2002:209), but this power makes them even more alluringly deceptive. Our goal in the remainder of this paper is to present a framework for videographic methodologies in LL studies that will allow researchers to use video as a tool while remembering that its moving images are just one representation of the material face of the Linguistic Landscape.

\section{Potential uses of videography in LL studies}

Before explaining a framework for videographic methodologies, we would like to briefly discuss the potential uses of video recordings for LL studies, some of which have already been used by researchers. Beginning with video as a tool for gathering research data, we can divide collection techniques into non-participatory and participatory. In the former, the researcher is either holding the camera and pointing it at the LL or the camera is held by an assistant with the researcher in the frame with the LL while other participants (sign producers, passers-by, etc.) are not subjects. There are several environmental types in which a video record may be a better collection tool than still photos. The signage along transportation routes can be difficult to capture with a still photo from a moving vehicle; thus, Hult (2014) explains how an assistant drove while the researcher operated a video camera to document roadside signage. More significantly, video allows a researcher to record the sequence of semiotic resources along a path of travel with each element entering and leaving the view in context. In a 2016 presentation by Lou, the investigator demonstrated how she had used this technique to study the LL while riding on public transportation. In both cases, video was a superior medium to still photographs for the reasons mentioned, but other situations may also be encountered such as when a narrow or crowded footpath does not allow a wide enough perspective to photograph the relationships among 
smaller units of analysis at a site. Section 5 "Capturing and conveying the LL" presents a case study in the use of video for documenting the LL in non-participatory situations.

Participatory data collection involves the cooperation of one or more LL agents, inhabitants, or passers-by. Video recording that does not happen on the LL site but in an office or research facility is a common practice in qualitative research where interviews can be recorded as well as participant interactions with simulations or example reproductions of an LL (Magnini, Miller, \& Kim, 2011). The greatest benefit of video-recorded participant data collection rests with the insights gained from interviews and walking tours conducted in the LL. Multimedia documentation of walking-in-the-LL makes it possible to study how people navigate their semiotic landscape in real-time. Further, such walking tours can highlight the embodied and situated nature of photography-in-the-LL, and they integrate visual documentation with on-site narration and conversation, thus (re)constructing interpretations of the sites during coexploration (Garvin, 2010; Stroud and Jegels, 2014). In Szabó's tourist guide technique (Laihonen \& Szabó, 2017; cf. walking tour methodology) school community members (students, teachers and parents) guided the researcher through their premises, interpreting the co-explored sites and co-constructing narratives of their daily school practices in conversation with the researcher. Participant-led tours are of special significance in inclusive research projects (e.g. Nind, 2014) in which the focus on the insights of research participants as local experts of places enhances multi-perspective approaches to reporting research results. Additionally, for both participatory and non-participatory videos, the ease through which digital video files can be shared via the internet allows colleagues who were not present at an LL site to collaborate more productively in the analysis of research materials.

All of these examples assume that the researcher is the creator of the video; however, as Kitis \& Milani (2015) demonstrate, LL studies can be informed by videos collected from online sources. As they briefly mention, in what we can call participant-created videos, "scene selection and choices of camera angle and size of shot lead to the creation of partial points-of-view that inevitably include certain actions and participants, while excluding or distorting others" (273). Their solution to this limitation was to draw from a wide variety of online video-sharing platforms while consciously including recordings produced by a "truly astounding spectrum of social actors, including activists, photographers, journalists, camera operators, commuters, and random witnesses or tourists" (274).

Following the collection and analysis of data, another important element of video recordings is their use in presenting the results of LL studies. These may be edited versions of data collected above or researcher-led 'tours' created for the purpose of conveying aspects of the LL to an audience that still photos cannot. Editing can include the addition of still photos to videos so that viewers can more clearly see what is being described by participants as well as the use of voice-over narration and superimposed captions. While this is most easily achieved by showing videos in person at conferences and workshops, we hope that in the near future the power of media-sharing platforms can be utilized for scholarly purposes. For several years it has been possible to embed digital videos into pfd files (at a larger, but not prohibitive, file size), which are the most common format for published articles and for dissertations. The same is true of ebooks except that due to the current lack of standardization of formats and reading devices, embedded videos would be of limited availability for monographs and edited volumes for purchase from publishers or the wider market. In all cases, however, accommodation must be made for purchasers of articles and books in traditional print format. Possible solutions for this challenge range from providing links to dedicated storage space on publisher's servers to files 
saved on local servers at researchers' institutions to collaborative archives created and maintained by LL scholars - any of which can be easily made available to the public or behind password-protected firewalls. While there is a risk that in the distant future linked video data may be lost, we contend that this risk is minimal compared to the potential benefits of collaboration that shared video enables in the present and near future.

In addition to the use of video by researchers, nearly all of the above methods can be adapted for pedagogical purposes from improving literacy and language awareness (Dagenais, et al., 2009) to language learning. Lee \& Choi (2016) explained how students of Korean as an L2 in a study abroad program created video LL tours as an element of their program. Malinowski (2015) is the most comprehensive contribution to date for application of LL studies to the second and foreign language learning syllabus. In his framework of perceived, conceived, and lived spaces, there are several opportunities for students to utilize and share video recordings: from documentation of the perceived, material LL (i.e., non-participatory data collection) to recording of off-site interviews with stakeholders to assess the conceived LL and on-site interviews with inhabitants to explore the lived space (both participatory data collection). Most promising is the potential for students to create imaginative or artistic multimodal projects which could include scenes from the aforementioned videos, scripted tours, and an unlimited number of more creative projects that include digital video as the primary or an additional medium.

As a final note regarding the possible uses of videography in LL studies, we would like to address public awareness. At a 2015 Linguistic Society of America conference colloquium (actually a "PechaKucha Datablitz") titled "Popularizing Linguistics through Online Media" a panel of speakers presented the benefits of expert-mediated-yet-user-generated media about language and linguistic information (Bigham, et al., 2015). On the topic of language policy and planning, Groom \& Littlemore (2000) pointed out that "some applied linguists have become powerful advocates of the linguistic human rights of minority language speakers in many countries, and have been increasingly successful in raising public awareness of these issues at local, national and international levels" (21). Yet Dagenais et al. (2009) explain that many of the students involved in their LL project were largely unaware of and attributed little significance to the LL before the project. Likewise, interviews with LL agents in Troyer, Cáceda, \& GiménezEguibar (2015) revealed that matters of language choice on public signage were seldom given conscious consideration until highlighted by the investigators.

The power of social media videos could, however, serve as a popular awareness raising tool. At the time of writing, a search for "Worldwide Accent Project," which started in 2010 on YouTube, generated about 20,000 results for videos in which a speaker reads a predetermined text in his or her most natural accent-many of these videos garnered more than 10,000 views each. Currently there are only a few YouTube videos about LLs; one of them is a well-conceived thirteen-minute program called "Linguistic Landscape, Tokyo" produced in Japanese by Tokyo Metropolitan University (2014) and subtitled in several languages, and another is a less formal fourteen-minute production titled "Linguistic Landscape of the Kensington Market" by two students at York University (Elliott \& Phillips-Boyle, 2014). We suggest that videos are potentially powerful tools for increasing public awareness of the LL especially in the form of relatively short videos featuring researchers or students who provide a tour of an LL with scripted or voice-over narration and which can contain edited fieldwork materials to provide insight into data collection and analysis processes-see for example the "Voices of Bullring Market" video created by the Arts and Humanities Research Council and the University of 
Birmingham (2015) for their Translation and Translanguaging project directed by Angela Creese.

\section{Methodological dimensions}

Although anthropologists have been working with ethnographic films as research tools and products for over 100 years, the use of the medium has not been uncontroversial (Garrett, 2010). According to Loizos, 1992 (cited in Garrett, 2010) though cameras and audio recorders gained early and widespread acceptance, anthropologists were slow to incorporate film/video recording devices. However, contemporary scholars of anthropology, human geography, sociology, and ethnographic methodologies have paved the way for uses of videography that are directly applicable to LL research (Rose, 2012; Pink 2007, 2008, etc.; Knoblauch, Schnettler, \& Raab, 2012). Despite the ubiquitous presence of user-produced digital video on social media, "the methodological discussion of their use in scholarly studies is greatly underdeveloped" (Knoblauch et al., 2012:9). Most people are familiar with the requisite technical choices when shooting a still photograph (angle, frame, composition of elements, lighting and color), but video production in research, although striving for naturalness, entails many more considerations. With this in mind, Knoblauch et al. (2012) explain the range of options using two graphically presented methodological dimensions and discussion of a possible third. Expanding on and adapting their framework, we have created Figure 1 in which the primary horizontal and vertical axes account for the situation and recording techniques respectively while two secondary dimensions allow consideration of the methods of data analysis and the purpose/audience. The examples we have provided on Figure 1 should not be understood as placed in fixed locations; they are intended to indicate potential uses of video recordings for LL research along prototypical dimensions as discussed below.

The horizontal axis along the top of Figure 1 indicates the situation that is being recorded on a scale from Natural to Artificial. Because inhabiting an LL means becoming part of a complex phenomenological experience, we first must critically consider the ability of a person with a camera to be 'natural.' Navigating a sidewalk with a path in mind and the intention of documenting the LL with a video camera is not a natural occurrence in the way that goal-directed behavior such as walking to the local market to buy fresh fruit is. It is, thus, with a caveat that we understand this axis: completely 'natural' recording (i.e., an unobtrusive, gaze-directed camera worn during non-research navigation of the LL) may not be a feasible method; however, when we understand that video is a technologically mediated representation, not a window, we can more accurately qualify the data that we record and describe its position on a relative scale of 'natural' to 'artificial.' With this caveat in mind, documenting the material face of the LL when no passers-by are present or when inhabitants are unaware of the documentation would qualify as highly natural circumstances. On the other hand, the presence of a researcher and camera on a walking tour may alter the interactions in the LL being documented leading it to be more or less of an artificial representation. An example of an even more artificial situation in the LL would be that of a researcher giving a scripted, guided tour for the benefit of an imagined audience. Recordings outside of the LL can be considered the least natural from video recordings, ranging from video of interviews regarding an actual LL to recordings of participants interacting with LL simulations in a lab setting. 


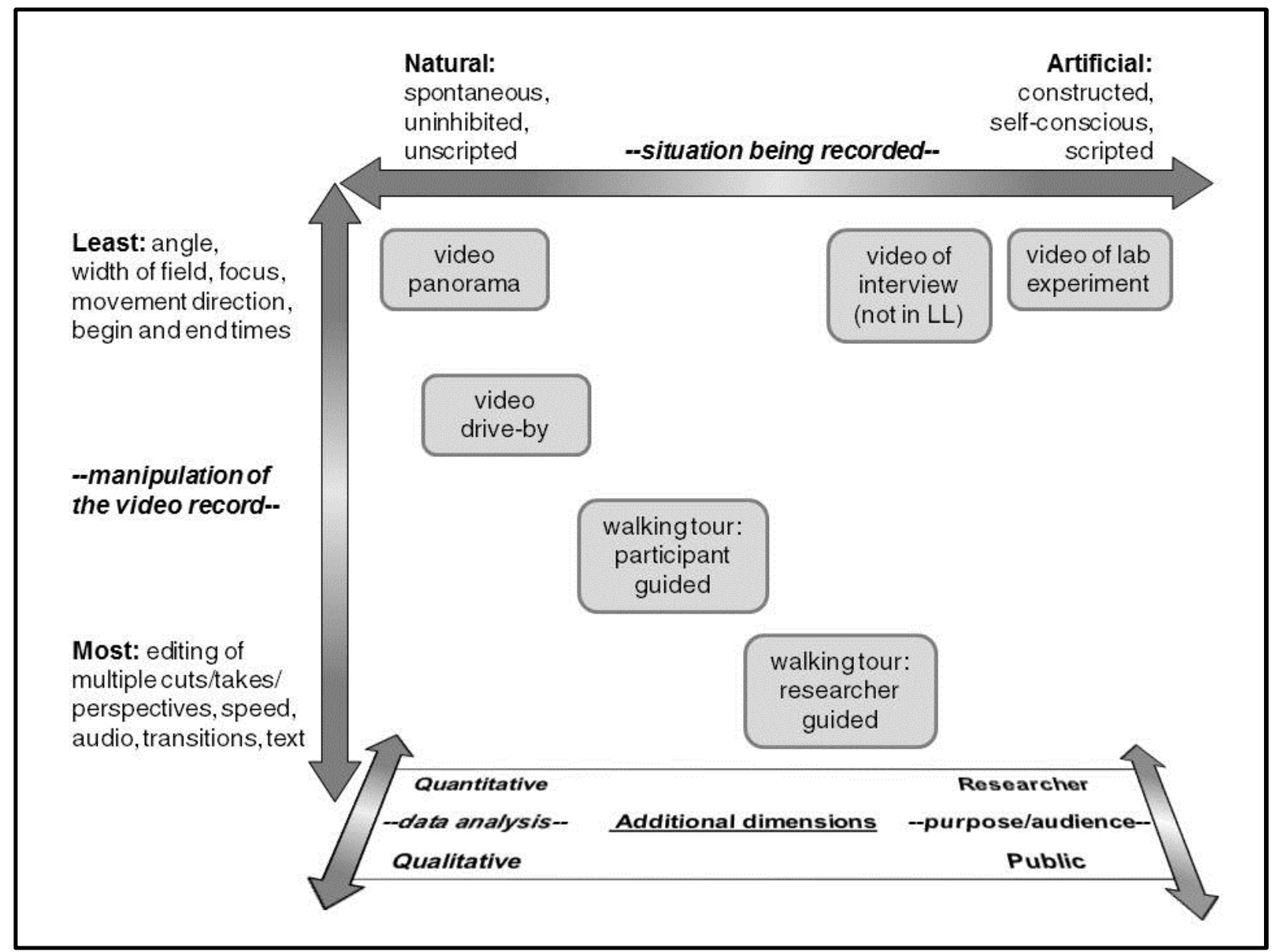

Figure 1. Methodological Dimensions of Videography for LL Studies

The vertical axis accounts for the technical aspects of videography, which in some cases are more complicated than similar considerations for still photography due to the ability of video to capture movement over time. According to Scriven (2013) the video camera restores "the corporeal presence of the researcher in the field... the unseen operator of the recording device" (66). When taking a still photograph, the height of the camera is more variable while the angle of the lens toward the subject is less (i.e., one may bend down to photograph a sign low to the ground at more level angle), but when shooting video, the camera nearly always remains at 'head-height' of the operator, thus, more forcefully imposing the perspective of an observer looking up, down, and around. Likewise, video camera movement implies intentional shifts of attention as different objects become foregrounded making it essential that the camera operator maintain full awareness of the degree of naturalness sought to be captured and the purposes the recording will serve. Similarly, a photograph of the LL typically captures a moment bereft of markers of time except for the lighting which suggests the time of day and/or signage that indicates the time (i.e., an "open" sign), or occasionally a passer-by in some state of action. In contrast, the starting and ending time of a video impose a causal sequence, a narrative associated with the point of view. Choosing when to begin, how long to record, and where the camera will 'look' are the minimal manipulations and they are in no way trivial. Further manipulations of the video record consist of editing the record which also entails choosing transitions, potentially shooting the same LL from different perspectives and combining them, altering the playback 
speed, including still images, adding or removing audio, and superimposing text onto the screen images. Thus, any one of the examples given on Figure 1 could easily be moved up or down the vertical axis; the degree of manipulation necessary will depend on the other variables located along the two third-dimensions indicated at the bottom of Figure 1.

These dual third dimensions relate to how and why the video will be viewed. The dimension, arbitrarily placed on the left, refers to the methods of data analysis. These arrows should not imply mutual exclusion or a true continuum, but a range of analytical choices that will affect the horizontal and vertical dimensions. If video will be used for quantitative research, careful attention to the unit(s) of analysis must be maintained so that each element is in focus long enough to be studied closely. On the other hand, if the investigator wants the video to represent with as much fidelity as possible the perspective of an inhabitant for qualitative analysis, a spontaneous walking tour in which the camera operator mimics the path and gaze of the participant tour guide would be appropriate. The final dimension involves the audience and purpose that the record will serve. A video intended to capture a researcher's first impression of navigating a new LL and to be used only by the researcher to inform a deepening ethnography may be oriented toward naturalness and little manipulation of the record. In contrast, a researcher who has documented and analyzed an LL, and who wishes to create a video that can inform an audience of the research findings may obtain various degrees of naturalness while containing a great deal of technical manipulation.

The dimensions accounted for in Figure 1 are intended to apply to researcher-created videos, but they can also be used to clarify the videographic processes behind participant-created recordings such as those used by Kitis \& Milani (2015), cited above. The difference between research and participant-created work can be captured in the additional dimension at the lower right-hand corner where 'researcher' may be replaced with 'participant'. Thus, this framework for videography can also be applied in LL studies that are informed by online ethnographic forms of data collection in order to specify the interaction between production methods, situation, authorship, and analytical methods of sources.

With the above framework in mind, it is important to remember that every video is a 'technical image' and, therefore, not a window onto objective reality, but a subjective perspective. As Garrett (2010) reminds us, "even if objective representations were possible, objective footage could not be objectively consumed. All visually representational mediums are chaotically triangulated constructions between the subjectivity of the cameraperson, participants and viewers" (527). Accordingly, Knoblauch \& Tuma (2011) assert that "the specific demands for how to produce the video recordings are revealed through the ethnographic work preceding it" (418). What the video representation will convey depends upon the situation, context, subjective knowledge of the LL stakeholders and the researchers, what elements of the LL are accessible and observable, the research questions, and disciplinary contexts. In order to manage these multiple variables, Knoblauch \& Tuma (418) recommend the following steps for videographic methods.

1) explorative visits to the field

2) determination of which situations to focus on (based in part on identification of common features of the phenomena being studied)

3) video data collection

4) internal data sampling (bottom-up coding leading to selection of relevant sequences) - an intertwined and iterative process

5) development of codes that are indexed to the video time frame 
6) selection of relevant situations for further scrutiny and/or collection

These steps were followed in the case study reported below in which one of the authors used non-participatory videography to re-see a familiar landscape that had been the subject of a previous study. Thus, section 5 demonstrates how the multiple decisions involved in videography and the iterative process of analyzing these LL representations can illuminate interpretations of a research site.

\section{Capturing and conveying the $L L$}

Even though the location studied in Troyer et al. (2015) is a town of only around 9,000 people on the west coast of the United States (Independence, Oregon), its streets have been photographed and recreated on Google Maps so that by entering the GPS coordinates ${ }^{3}$ and zooming down to street view, nearly anyone can take a virtual tour of the town. At the time of writing, the Google photos of side-streets had been taken in 2012 while the main streets were updated in 2015 and 2016 - data for the study published in Troyer et al. (2015) were collected in 2012 and 2013. As Troyer (2016) noted in a review of Blackwood et al. (2016), the ability to use geolocation programs like Google Maps to view sites of published LL studies is an important technological advancement that allows readers of LL studies to explore locations and gain valuable context that is not able to be included in an article or book chapter. As more of the mapped and photographed world is made available online, we urge LL scholars to begin including specific GPS coordinates and dates of data collection in their published work so that these tools can be used more effectively.

However, even in cities that have been photographed, not all significant LL locations will have been included. In the aforementioned town of Independence, one 'magnet' of Spanish/Latino presence in the LL was a shopping plaza containing two Mexican restaurants, a store selling food and small goods from Mexico, a Latina-owned beauty salon and other businesses with some signage in Spanish. Almost none of this variety is visible from the main street where the Google Maps photographs were taken. The rest of this section will explain this author's process of using the digital camera on his phone along with video editing software that is standard on a tablet computer to document and analyze the $\mathrm{LL}$ and then create a video (Online Appendix ${ }^{4}$ ) intended for an audience to convey one aspect of this site of study.

When collecting data for the original study, the lead author systematically photographed all of the signage visible along the main streets and parking area of the shopping plaza. While this was an effective method that allowed both quantitative and qualitative analysis that was supplemented by interviews with several LL agents and the ethnographic insights of the researchers who happened to reside in and around the town, approaching one of the sites with a video camera afforded additional insights. The earlier process of standing in front of the businesses in the shopping plaza and photographing their storefronts was a relatively simple production of Flusser's 'technical' images which were highly 'theoretical' because their point of view was from standing still in a parking lot where one would normally be driving or walking toward a specific location. However, documenting with video required conceptualizing the construction of the visual representation. The author chose to put himself in the position of a person exiting a vehicle at one end of the parking area and looking from the near end of the plaza to the opposite end in order to orient to the surroundings. This was followed by a drive-by video in which an assistant drove slowly in front of the line of stores (in the morning before many customers were present) while the author held the camera in a steady position that allowed the 
entirety of each store from top to bottom to be seen. Though not as naturalistic as possible, this perspective is very similar to that of a typical inhabitant looking out a vehicle window while passing by the line of shopfronts. The author chose this perspective with the intention of recreating his own experience of this LL which he had stood in and driven through regularly during his eight years of residence in the community.

Later, watching the video, one element of the LL that had been less salient while studying the still photos was the stark contrast of storefront aesthetics between the 'Latino' businesses and the other shops. Nearly every store in the shopping plaza has a storefront constructed of end-toend windows from two feet off the sidewalk to the shop ceiling. The vast majority of businesses did not display any Spanish, and featured a large horizontal sign centered above the window providing the name of the business and often images or secondary text. The display windows on these shops were almost entirely bare, allowing customers to see inside. Very often, however, some windows would have one large or small sign mounted inside and facing out; these ranged from lighted 'open' signs to professionally produced posters that if large, were squarely centered on the window, or if small were set in a corner. In the video, store after store passes by from right to left, each one nearly identical in design until the store featuring goods from a specific province of Mexico appears in technicolor contrast. Nearly every window pane was filled with stenciled letters, handmade signs, and advertising posters of a wide variety of sizes and colors displaying the range of goods for sale from phone cards to fruit smoothies to school uniforms. As this store passes from the screen, the next store, a large one on the corner, reverts to the default minimalist aesthetic; rounding the corner, window after window passes until a Mexican restaurant comes into view with orange, stuccoed walls fitted with small arched windows framed in brick and every window decorated with painted banners and stereotypical imagery (sombrero, cactus, margarita glass, man on a burro, etc.).

Revisioning the LL with video foregrounded these aesthetic differences and led to further examination of other sites in the town that resulted in the following conclusions when combined with previously collected data. Storefront aesthetics that featured Spanish and were markedly different from the majority of storefronts in the town pointed toward three orientations: 1) commodification, 2) authenticity, or 3) functional pragmatics. Only one of the locations, the restaurant described above, which was not locally-owned, relied solely on stereotypical images, colors, and Spanish words that are easily recognized by most Americans to attract customers. We interpret these appeals as examples of cultural commodification similar to the situation in DC's Chinatown discussed in Leeman \& Modan (2009:338). In contrast, the displays of other Latino businesses were oriented toward authenticity; for example, a neighboring Mexican restaurant, the store also described above, and a larger market selling fresh meat, produce and goods with a taquería inside displayed original images designed by the owners and/or a combination of posters featuring items very specific to that store. According to two of the owners/managers who designed the displays, their storefronts were intended not only to draw attention by being different but to convey vibrancy that is authentic and an expression of their identity which sometimes includes bright colors, images from their homelands, and carnivalesque fonts and decorations.

A functional orientation was present in the aesthetic choices present on the two convenience stores that displayed a great deal of Spanish quickly conveyed to customers what is for sale with entire display windows filled with page sized promotions for international phone cards from different companies, overlapping soccer-themed beer advertisements, multiple lottery choices, and prominent food options: tacos, burritos, tortillas. These stores contained similar 
kinds of items that are available at other convenience stores that are part of national franchises, but the storefront aesthetics are very different. The stores that contained little or no Spanish were more similar to the large upscale grocery store in town with large, glossy posters framed by clear window space.

After reaching these brief conclusions which are an extension of the qualitative and quantitative results reported in Troyer et al. (2015), this author sought to create a short video that would highlight these aesthetic contrasts for an audience. Produced using only the basic videoediting application included on an ipad (Apple iMovie), the 75-second video begins with the panoramic establishing shot that provides the overall context of the shopping plaza.

Superimposed on this image in the lower left corner are the GPS coordinates for the location and the date, day, and time of the recording. A quick fade transitions to the drive-by sequence also with the date, day, and time of recording superimposed-as LL scholarship becomes more concerned with mobility and dynamic change (O'Connor \& Zentz, 2016) environmental variables such as day of the week and time of day that influence who and what is present in representations of the LL will become increasingly important. With the understanding that the video is a representation, not a window on authentic human experience, researchers are free to manipulate the record in order to convey their informed perspective on the LL as long as these manipulations are explained to viewers.

In the case of this video, the purpose was to foreground the contrasting aesthetics of the non-Latino businesses and the Latino ones, but in a short amount of time. This could be achieved without presenting the entire drive-by sequence, so some repetitive facades were cut unobtrusively and the play speed was increased until the Mexican store was reached. Figure 2 is a still shot from the video showing at left the window (blinds drawn) of the adjacent business and the first two windows of the Mexican store. With the Mexican store centered in the video, the movement pauses momentarily so the viewer has more time to process the unique shopfront. More windows pass and then the commodified Mexican restaurant appears in a blaze of orange that soon returns to typical display windows. Figure 3 shows the last window of the store to left and the entrance to the restaurant. Following the restaurant the video pauses at a store with typical displays but a one with a sign in Spanish then continues but skips some repetitive displays in order to end the drive-by with the large, upscale grocery store (Figure 4). A fade transition then opens on an establishing shot of one of the convenience stores followed by a slow walk-by passing from left to right in front of the windows so that individual signage is visible (Figure 5). 


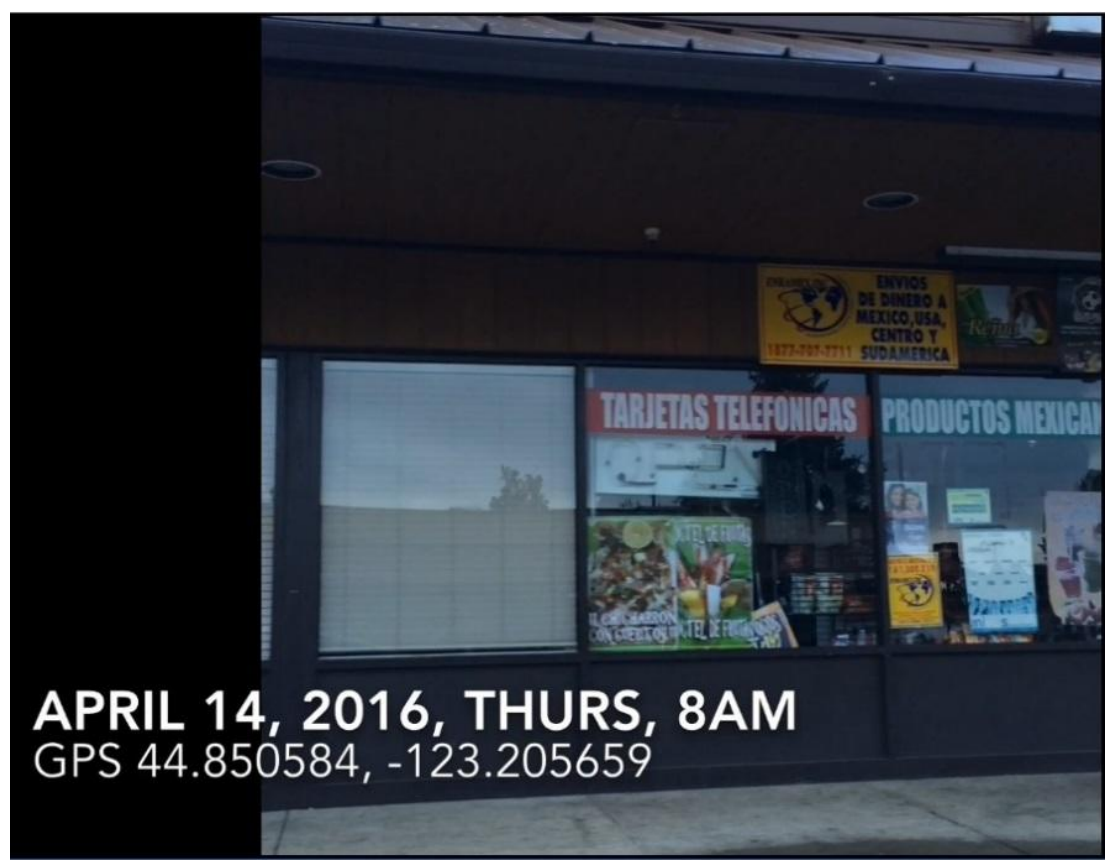

Figure 2. Still frame from video at 18 seconds

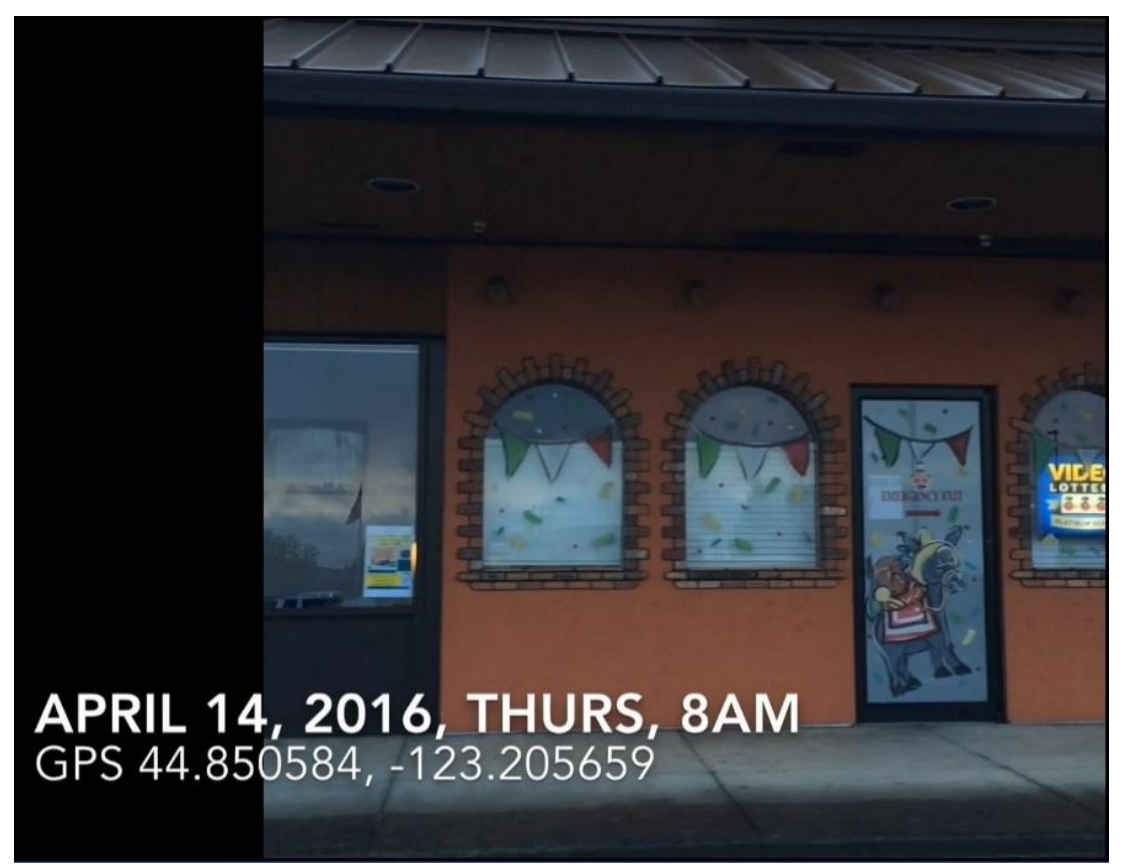

Figure 3. Still frame from video at 28 seconds 


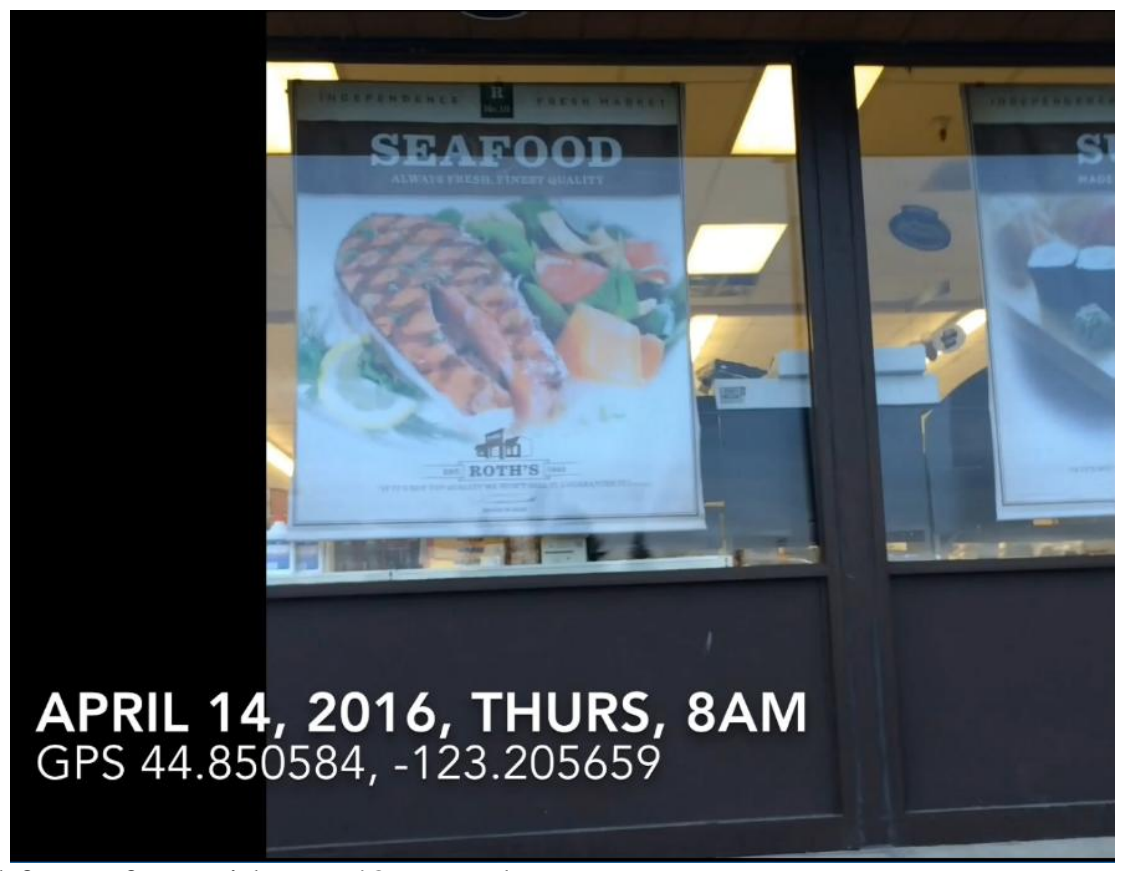

Figure 4. Still frame from video at 48 seconds

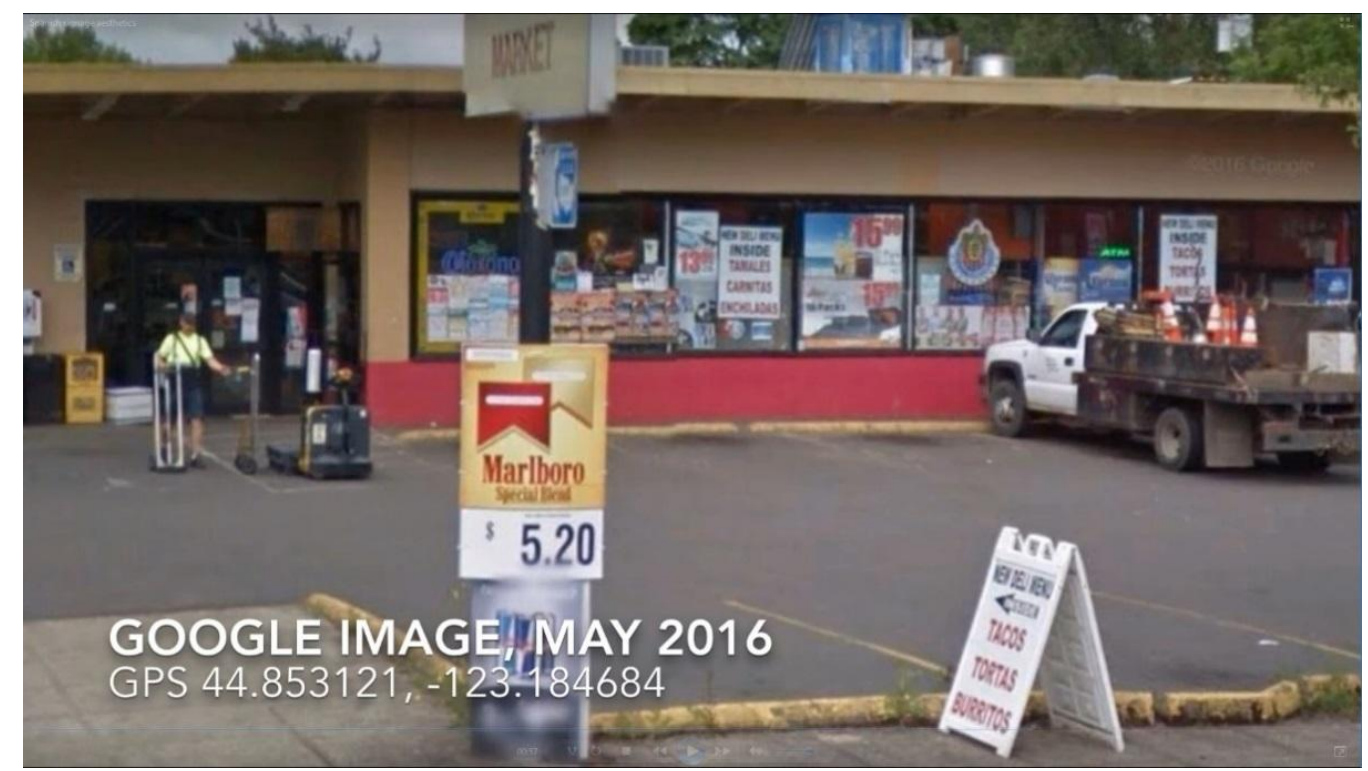

Figure 5. Still frame from video at 58 seconds

This example use of video highlights the role of representations of the LL. When investigators acknowledge their methods of image collection such as according to a framework like Figure 1, representations become less alluring and more informative. In this case, the final video (Online Appendix) is oriented toward capturing a natural setting (albeit from a consciously planned perspective), but due to its purpose to convey an interpretation of the LL, it is heavily edited. Photos and videos intended for data collection serve a different purpose from those intended to supplement interpretations of the LL which puts the onus on researchers to indicate how they have manipulated their materials. 


\section{Conclusion}

"The struggle of writing against the image... runs throughout history" (Flusser, 2000:11).

For an LL scholar, one data point, the photo of a sign, may contain just one word, yet the adage is true: a picture is worth a thousand words. Flusser's statement above expresses the conflict between, on one hand, the technical images that researchers collect as data and select as exemplars for publication, and on the other hand, the analysis and discussion that they write and present. Technical images including multimedia are powerful tools, but they are only one window at one moment onto a historical discourse. Digital video, which is now easily captured, edited, and viewed online, may prove to be the next evolution of LL studies (at least technologically), but it too is a technical reproduction. We hope that this article has raised awareness of the role that photographs and videos play as visual representations of the LLmediated reconstructions that for all of their potential as records and displays, are simulacra of the lived experience of language in the landscape - and that the suggested framework for LL videography can inform future studies.

\section{Notes}

1. In 2008 Polaroid, the most well-known manufacture of 'instant film and cameras' since the 1950s, filed for bankruptcy.

2. The authors are indebted to Durk Gorter for providing the reference to Flusser (1983) in his 2016 paper at AAAL and to Jeffery Kallen for his presentation on framing and perspective at the 2015 LL7 workshop at Berkeley.

3. $44.851199,-123.215241$ to $44.851127,-123.184524$; and $44.848308,-123.184548$ to $44.868122,-123.186040$

4. The Online Appendix is available at http://digitalcommons.wou.edu/english_facpubs/1/

\section{Acknowledgments}

The authors wish to thank the anonymous reviewers of the earlier drafts of this article for their insightful comments and suggestions.

\section{References}

Berger, J. (1972). Ways of Seeing. London: BBC and Penguin.

Bigham, D., Curzan, A., Erard, M., Maune, M., Okrent, A., McCulloch, G., Whiteman, N., \& Zimmer, B. (2015, January). Popularizing Linguistics through Online Media. Presentation at the annual Linguistic Society of America Conference, Portland, Oregon.

Blackwood, R. J., Lanza, E., \& Woldemariam, H. (Eds.). (2016). Negotiating and Contesting Identities in Linguistic Landscapes. London: Bloomsbury Publishing.

Blommaert, J. (2013). Ethnography, Superdiversity and Linguistic Landscapes. Bristol: Multilingual Matters.

Brown, K. D. (2012). The linguistic landscape of educational spaces: Language revitalization and schools in Southeastern Estonia. In D. Gorter, H. F. Marten, \& L. V. Mensel (Eds.), 
Minority Languages in the Linguistic Landscape (pp. 281-298). Basingstoke: Palgrave Macmillan.

Bucholtz, M. \& Hall, K. (2016). Embodied sociolinguistics. In N. Coupland (Ed.), Sociolinguistics: Theoretical Debates (pp. 173-197). Cambridge: Cambridge UP.

Dagenais, D., Moore, D., Sabatier, C., Lamarre, P., \& Armand, F. (2009). Linguistic landscape and language awareness. In E. Shohamy \& D. Gorter (Eds.), Linguistic Landscape: Expanding the Scenery (pp. 253-269). New York: Routledge.

Elliott, L. \& Phillips-Boyle, S. (Producers). (2014, Sept 25). Linguistic Landscape of the Kensington Market [Video file]. Retrieved from $\mathrm{https} / / / \mathrm{www}$. youtube.com/watch? $\mathrm{v}=\mathrm{mTAz} 0 \mathrm{sDWGcs}$

Flusser, V. (2000). Towards a Philosophy of Photography. (A. Mathews, Trans.) London: Reaktion. (Original work published 1983).

Garrett, B. L. (2010). Videographic geographies: Using digital video for geographic research. Progress in Human Geography, 35(4) 521-541.

Garvin, R. (2010). Responses to the linguistic landscape in Memphis, Tennessee: An urban space in Transition. In E. Shohamy, E. Ben-Rafael, \& M. Barni (Eds.), Linguistic Landscape in the City (pp. 252-271). Bristol: Multilingual Matters.

Gold, JR. (2002). The real thing? Contesting the myth of documentary realism through classroom analysis of films on planning and reconstruction. In T. Cresswell and D. Dixon D (Eds.), Engaging Film: Geographies of Mobility and Identity (pp. 209-225). Lanham, MD: Rowman and Littlefield.

Gorter, D. (2006). Introduction: The study of linguistic landscape as a new approach to multilingualism. In D. Gorter (Ed.), Linguistic Landscape: A New Approach to Multilingualism (pp. 1-6). Clevedon: Multilingual Matters.

Gorter, D. (2013). Linguistic Landscapes in a Multilingual World. Annual Review of Applied Linguistics, 33, 190-212.

Gorter, D., \& Cenoz, J. (2015). Linguistic landscapes inside multilingual schools. In B. Spolsky, O. Inbar-Lourie, \& M. Tannenbaum (Eds.), Challenges for Language Education and Policy (pp. 151-169). New York: Routledge.

Groom, N. \& Littlemore, J. (2011). Doing Applied Linguistics: A Guide for Students. Oxon: Routledge.

Hult, F. M. (2014). Drive-thru linguistic landscaping: Constructing a linguistically dominant place in a bilingual space. International Journal of Bilingualism, 18(5), 507-523.

Ivkovic, D., \& Lotherington, H. (2009). Multilingualism in cyberspace: Conceptualising the virtual linguistic landscape. International Journal of Multilingualism, 6(1), 17-36. http://doi.org/10.1080/14790710802582436

Kallen, J. (2016, April). Semiotic Landscapes and Literary Imagination in James Joyce's Ulysses. Presentation at the Linguistic Landscape 8 Workshop, Liverpool, England.

Kitis, D., E., \& Milani, T. M. (2015). The performativity of the body. Linguistic Landscape: An International Journal, 1(3), 268-290.

Knoblauch, H., Schnettler, B., \& Raab, J. (2012). Video-Analysis: Methodological Aspects of Interpretive Audiovisual Analysis in Social Research. In H. Knoblauch, B. Schnettler, J. Raab, \& H. Soeffner (Eds.), Video Analysis: Methodology and Methods: Qualitative Audiovisual Data Analysis in Sociology, 3rd ed (pp. 9-26). Frankfurt: Peter Lang. 
Knoblauch, H., \& Tuma, R. (2011). Videography: An interpretative approach to analyzing video recorded social interaction. In E. Margolis and L. Pauwels (Eds.), The SAGE Handbook of Visual Research Methods (pp. 414-430). London: SAGE.

Laihonen, P. \& Szabó, T. P. (2017). Investigating visual practices in educational settings: schoolscapes, language ideologies and organizational cultures. In M. Martin-Jones \& D. Martin (Eds.), Researching multilingualism: Critical and ethnographic approaches (pp. 121-138). London: Routledge.

Landry, R., \& Bourhis, R. Y. (1997). Linguistic landscape and ethnolinguistic vitality: An empirical study. Journal of Language and Social Psychology, 16(1), 23-49. http://doi.org/10.1177/0261927X970161002

Lee, H., \& Choi, B. (2016, April). A Geolocative Linguistic Landscape Project in Korean Language Education. Presentation at the annual American Association of Applied Linguistics Conference, Orlando, Florida.

Leeman, J., \& Modan, G. (2009). Commodified language in Chinatown: A contextualized approach to linguistic landscape. Journal of Sociolinguistics, 13(3), 332-362.

Lou, Jackie Jia. (2016, April). Ways of Walking, Ways of Seeing: Doing Mobile Video Ethnography in Linguistic Landscape Research. Presentation at the annual American Association of Applied Linguistics Conference, Orlando, Florida.

Magnini, V. P., Miller, T., \& Kim, B. (Peter). (2011). The psychological effects of foreignlanguage restaurant signs on potential diners. Journal of Hospitality \& Tourism Research, 35(1), 24-44. http://doi.org/10.1177/1096348010370753

Malinowski, D. (2010). Showing seeing in the Korean linguistic cityscape. In E. Shohamy, E. Ben-Rafael, \& M. Barni (Eds.), Linguistic Landscape in the City (pp. 199-215). Bristol: Multilingual Matters.

Malinowski, D. (2015). Opening spaces of learning in the linguistic landscape. Linguistic Landscape: An International Journal, 1(1/2), 95-113. http://doi.org/10.1075/11.1.1$2.06 \mathrm{mal}$

Nind, M. (2014). What is Inclusive Research? London: Bloomsbury.

O'Connor, B., H., \& Zentz, L. (2016). Theorizing mobility in semiotic landscapes: Evidence from South Texas and Central Java. Linguistic Landscape: An International Journal, 2(1), 26-51. https://doi.org/10.1075/11.2.1.02oco

Peck, A., \& Stroud, C. (2015). Skinscapes. Linguistic Landscape: An International Journal, 1(1/2), 133-151. http://doi.org/10.1075/11.1.1-2.08pec

Pennycook, A. (2009). Linguistic landscapes and the transgressive semiotics of graffiti. In E. Shohamy \& D. Gorter (Eds.), Linguistic Landscape: Expanding the Scenery (pp. 302312). New York: Routledge.

Pennycook, A. (2010). Spatial narrations: Graffscapes and city souls. In A. Jaworski \& C. Thurlow (Eds.), Semiotic Landscapes: Language, Image, Space (pp. 137-150). London: Continuum.

Pennycook, A., \& Otsuji, E. (2015). Making scents of the landscape. Linguistic Landscape: An International Journal, 1(3), 191-212. http://doi.org/10.1075/11.1.3.01pen

Pink, S. (2007). Walking with video. Visual Studies, 22(3), 240-252.

Pink, S. (2008). An urban tour: The sensory sociality of ethnographic place-making. Ethnography, 9(2), 175-196.

Rubdi, R., \& Ben Said, S. (2015). Conflict, Exclusion and Dissent in the Linguistic Landscape. Basingstoke: Palgrave Macmillan. 
Scriven, R. (2012-13). Video methodologies and engaging with mobilities. Chimera: Geographical Journal, University College Cork, 26, 64-74.

Shohamy, E., \& Gorter, D. (2009). Introduction. In E. Shohamy \& D. Gorter (Eds.), Linguistic Landscape: Expanding the Scenery (pp. 1-10). New York: Routledge.

Shohamy, E., \& Waksman, S. (2009). Linguistic landscape as an ecological arena: Modalities, meanings, negotiations, education. In E. Shohamy \& D. Gorter (Eds.), Linguistic Landscape: Expanding the Scenery (pp. 313-331). New York: Routledge.

Stroud, C., \& Jegels, D. (2014). Semiotic landscapes and mobile narrations of place: Performing the local. International Journal of the Sociology of Language, 2014(228), 179-199.

Szabó, T. P. (2015). The Management of Diversity in Schoolscapes: An Analysis of Hungarian Practices. Apples - Journal of Applied Language Studies, 9(1), 23-51.

Tokyo Metropolitan University (Producer). (2014, Nov 19). Linguistic Landscape, Tokyo - with English Subtitles [Video file]. Retrieved from https://www.youtube.com/watch?v=RnwByvSl_gE

Troyer, R. A. (2012). English in the Thai linguistic netscape. World Englishes, 31(1), 93-112. http://doi.org/10.1111/j.1467-971X.2011.01742.x

Troyer, R. A. (2016). [Review of the book Negotiating and Contesting Identities in Linguistic Landscapes, by R. Blackwood, E. Lanza, \& H. Woldeemariam (Eds.)]. Manusya: Journal of the Humanities, 2016 (Special Issue 22): 88-93. Retrieved from http://www.manusya.journals.chula.ac.th/html/issue_detail.php?issue $=70$

Troyer, R. A., Cáceda, C., \& Giménez-Eguibar, P. (2015). Unseen Spanish in Small-Town America: A Minority Language in the Linguistic Landscape. In R. Rudby \& S. Ben Said (Eds.), Conflict, Exclusion and Dissent in the Linguistic Landscape (pp. 52-76). Basingstoke: Palgrave Macmillan.

[University of Birmingham]. (2015, March 4). Voices of the Bullring Markets. [Video file]. Retrieved from https://www.youtube.com/watch? $\mathrm{v}=\mathrm{Ea} 1 \mathrm{rPkt} 82 \mathrm{~ms}$

\author{
Authors' addresses \\ Robert A. Troyer \\ Western Oregon University \\ Department of English, Writing, \& Linguistics \\ 345 Monmouth Ave N. \\ Monmouth, OR 97361 \\ USA \\ troyerr@wou.edu \\ Tamás Péter Szabó \\ University of Jyväskylä \\ P. O. Box 35 \\ Jyväskylä, FI-40014 \\ Finland \\ tamas.p.szabo@jyu.fi
}

